\title{
A new pathological system for grading DCIS with improved prediction of local recurrence: results from the UKCCCR/ANZ DCIS trial
}

\section{SE Pinder ${ }^{*, I}, C_{\text {Duggan }}{ }^{2}$, IO Ellis ${ }^{3}$, J Cuzick ${ }^{4}$, JF Forbes ${ }^{5}, \mathrm{H}_{\text {Bishop }}$, IS Fentiman ${ }^{7}$ and WD George ${ }^{8}$, on behalf of the UK Coordinating Committee on Cancer Research (UKCCCR) Ductal Carcinoma In Situ (DCIS) Working Party}

'King's College London, Division of Cancer Studies, Research Oncology, $3^{\text {rd }}$ Floor, Bermondsey Wing, Guy's Hospital, Great Maze Pond, London SEI 9RT, UK; ${ }^{2}$ Department of Epidemiology, Public Health Sciences, Fred Hutchinson Cancer Research Center, Seattle, WA, USA; ${ }^{3}$ Histopathology Department, Molecular Medical Sciences, Nottingham University, Nottingham City Hospital, Nottingham, UK; ${ }^{4}$ Cancer Research UK Centre for Epidemiology, Mathematics and Statistics, Queen Mary University of London, London, UK; ${ }^{5}$ School of Medical Practice and Population Health, University of Newcastle, NSW, Australia; 'Department of Breast Surgery, Royal Bolton Hospital, Bolton Hospitals NHS Trust, Lancs, UK; ${ }^{7}$ Breast Unit, Guy's Hospital, London, UK; ${ }^{8}$ University Department of Surgery, Western Infirmary, Glasgow, UK

BACKGROUND: There is no consensus agreement regarding optimal management of locally excised ductal carcinoma in situ (DCIS) or features of greatest assistance in predicting disease behaviour. Cases in the UKCCCR/ANZ DCIS trial have been histologically reviewed to determine the features of prognostic importance.

METHOD: A total of $72 \%$ of 1694 cases entered into the UKCCCR/ANZ DCIS trial had full pathological review. A large number of histological features were assessed, blinded to outcome and compared regarding ability to predict ipsilateral recurrence, as either DCIS or progression to invasive carcinoma.

RESULTS: Pathological features associated with ipsilateral recurrence in univariate analysis included high cytonuclear grade, larger lesion size, growth pattern, presence of necrosis or chronic inflammation, incompleteness (or uncertainty of completeness) of excision and smaller margin width. Receipt of post-operative radiotherapy was also a strong prognostic factor.

We report a novel sub-division of the large group of high-grade lesions, which enables identification of a very poor prognosis subgroup; namely, DCIS that is of high cytonuclear grade, predominantly ( $>50 \%$ ) solid architecture, bearing extensive comedo-type necrosis ( $>50 \%$ of ducts). In addition, we found little difference in ipsilateral recurrence rates between low- and intermediate-grade groups. Hazard ratios for low, intermediate, high and the new, very high, grade were 0.42, 0.33, 0.62 and I.00, respectively, for ipsilateral in situ or invasive recurrence.

CONCLUSION: We present a novel pathological classification for DCIS with substantially better prognostic discrimination for ipsilateral recurrence than the classical categorisation based on cytonuclear grade alone.

British Journal of Cancer (2010) 103, 94- 100. doi:I0.1038/sj.bjc.66057I8 www.bjcancer.com

Published online I June 2010

(c) 2010 Cancer Research UK

Keywords: ductal carcinoma in situ; prognosis; histopathology

Mammographic breast screening facilitates the diagnosis of ductal carcinoma in situ (DCIS) (Anderson et al, 1991) and the apparent incidence has increased as a result (Baxter et al, 2004). Thus, DCIS comprised $21 \%$ of screen-detected breast carcinoma in the United Kingdom in 2006-2007 (NHS Breast Screening Programme. Annual Review, 2008). In the early 1990s, three large randomised clinical trials began recruiting with the aim of assessing the safety of breast conserving surgery (BCS) for DCIS and the requirement for subsequent radiotherapy (RT) in women having wide local excision (WLE) for DCIS. The NSABP B-17 (Fisher et al, 1998, 1999b) and EORTC 10853 trials (Julien et al, 2000; Bijker et al, 2001, 2006), as well as the UKCCCR/ANZ DCIS trial

*Correspondence: Professor SE Pinder; E-mail: sarah.pinder@kcl.ac.uk Received 17 February 20 I0; revised 30 April 20 I0; accepted 5 May 20 I0; published online I June 2010
(UK Coordinating Committee on Cancer Research Ductal Carcinoma in situ Working Party, 2003) recruited patients diagnosed with DCIS in the early 1990s and have already presented results comparing complete surgical excision with and without RT. Two of these trials (Fisher et al, 1999a; UK Coordinating Committee on Cancer Research Ductal Carcinoma in situ Working Party, 2003) also addressed the effect of the addition of tamoxifen to complete local excision in the management of DCIS.

The clinical management of patients with DCIS changed during the 1990s, but, despite the large reduction of local recurrence risk from RT after BCS for DCIS, only $57 \%$ of women have RT after BCS in the United Kingdom (Dodwell et al, 2007). There is a widespread belief that not all patients with DCIS require RT. However, the search for features that can assist in this clinical decision-making process remains unresolved (Silverstein et al, 1996; Sakorafas and Farley, 2003). 


\section{MATERIALS AND METHODS}

The UKCCCR DCIS trial was a $2 \times 2$ factorial randomised clinical trial comparing complete WLE alone with WLE plus RT to the residual ipsilateral breast tissue. Two further arms consisted of WLE followed by tamoxifen and WLE plus RT and tamoxifen. The dose of tamoxifen was $20 \mathrm{mg}$ daily taken for 5 years. Patients receiving RT were given supervoltage treatment with opposed tangential fields that included the breast and the axillary tail. A dose of $50 \mathrm{~Gy}$ in 25 fractions over 5 weeks was suggested. No boost was recommended.

Patients had unilateral or bilateral DCIS detected through the UK National Health Service Breast Screening Programme, which was considered suitable for BCS. The Australian-New Zealand Breast Cancer Trials Group also participated in the trial. Patients with microinvasive carcinoma ( $<1 \mathrm{~mm}$ in maximum dimension) were eligible for inclusion. Exclusion criteria included a diagnosis of atypical ductal hyperplasia, lobular carcinoma in situ or Paget's disease of the nipple. Patients gave witnessed, written or verbal consent for inclusion, and local ethics approval was obtained in all centres recruiting patients.

After randomisation and treatment, patients were followed up as per local protocol. Dates of relapse (ipsilateral or contralateral), diagnosis of new, non-breast malignant disease and death (breast cancer-related or not) were recorded.

\section{Histological review}

Representative material was sought from the surgical excision. Slides were examined by a single breast pathologist (SEP) and a large number of histological features were recorded in a database (see Table 1). Any cases that on review showed histological features, which were not sufficient for the diagnosis of DCIS, or which showed an invasive focus, were reviewed and the diagnosis confirmed by a second pathologist (IOE).

\section{Features recorded}

The histological features of DCIS assessed are shown in Table 1. For some of these, criteria had to be specifically defined as, after literature and guideline review, it was found that no globally agreed definitions could be applied. For example, for the purposes of this study, comedo DCIS was defined specifically as (i) highgrade DCIS with (ii) central confluent necrosis and (iii) solid architectural pattern in $>50 \%$ of the involved duct spaces. All these features had to be present for classification of pure comedo

Table I Univariate analysis - recurrence of ipsilateral DCIS or invasive disease

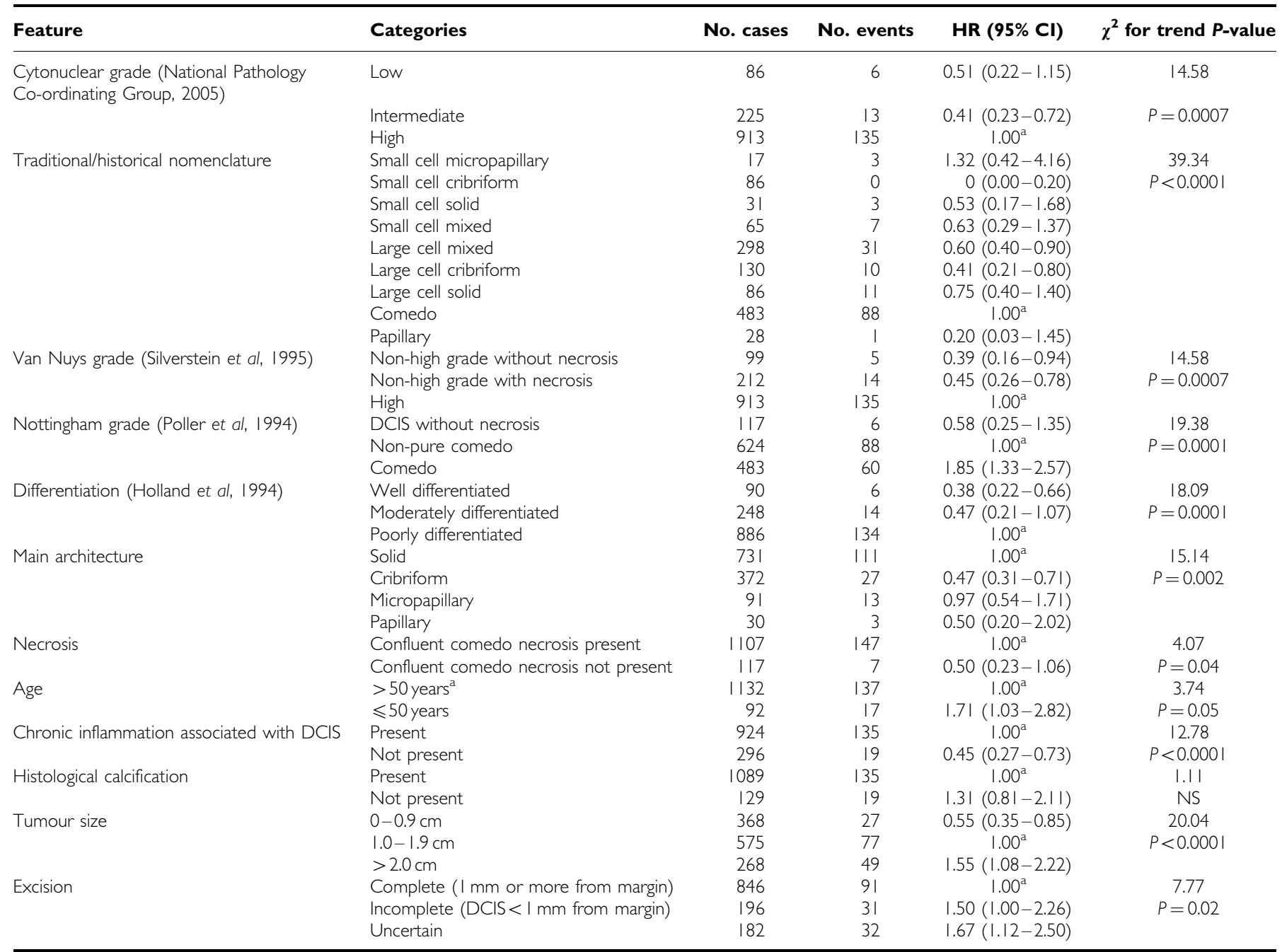

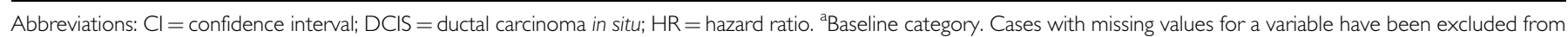
that analysis. 
disease in both the traditional sub-type categorisation and for 'Nottingham' DCIS grade.

The original clinical protocol for the UKCCCR DCIS trial required complete excision of DCIS, but no margin width was defined. Review of completeness of excision and margin width is problematic within the auspices of a central pathology view. However, the evaluation of margin status and distance was determined on a case-by-case basis, taking into account the original histology report, number and orientation of specimens and the histological review, in which the distance $(\mathrm{mm})$ to the nearest margin was measured on the histological sections received using the Vernier scale of the microscope. For the purposes of the present analysis, a distance of $1 \mathrm{~mm}$ or more from the nearest margin was defined as complete excision. Thus, if DCIS was stated to be $1 \mathrm{~mm}$ or more from the surgical margin (or completely excised) in the original report, and this was confirmed on review, excision was deemed complete. Excision was recorded as incomplete if DCIS extended to $<1 \mathrm{~mm}$ from the margin in the original histology report (or was stated to be incompletely excised) and in the reviewed slides. Excision was coded as uncertain, when multiple pieces of unorientated tissue were received by the original pathologist or excision was stated as uncertain in original report (and no subsequent surgical procedure undertaken) or there was a discrepancy between the review and original report that could not be explained taking all features into account.

For determination of size of DCIS, the larger of the measurements of maximal dimension from either the original report or review of histological sections was recorded. If there was DCIS in first and any subsequent re-excision, or several pieces of tissue were excised bearing DCIS, the measurements were summed (recognising that this would be an approximation and would generally be an overestimate of total size). In some cases, size could not be assessed on review and was not recorded in the original histology report.

The presence and degree of associated chronic inflammation was recorded. This was typically immediately adjacent to the involved ducts spaces and some cases included nodular aggregates of lymphoid cells, with lymphoid follicle formation. In other cases, this was seen as a complete, targetoid, peri-ductal population of lymphoid cells. This was assessed in a semi-quantitative manner and scored as absent, mild, moderate or marked.

\section{RESULTS}

Treatment comparison analyses have been presented earlier (UK Coordinating Committee on Cancer Research Ductal Carcinoma in situ Working Party, 2003). Here, we present results from the histological review with the same follow-up. Between May 1990 and August 1998, 1701 patients were entered into the trial. Seven were excluded because of protocol violations (earlier malignant disease, treated by mastectomy, known to have invasive carcinoma) ( $n=1694$ patients in total in the trial overall).

The number of slides submitted for pathological review varied (range 0-64 per case), with some laboratories submitting all slides, whereas others sent one representative slide or block (total number of sections 9649, mean 7.6, median 5 slides per case). On review, 33 patients were found to have earlier undiagnosed invasive carcinoma in the sections submitted (usually small and low grade) and were excluded from analysis. Twenty patients were not proven to have DCIS; in these cases, additional material was sought from the originating laboratory and reviewed, but no DCIS was identified in any of the material sent.

Sections were unavailable, or could not be retrieved, from 300 patients; these were not from any particular unit, coordinating centre or trial arm. Incomplete review data were available on a further 117 patients (e.g. the section submitted bore insufficient DCIS for a complete assessment). A total of 1224 (72.3\%) patients had full data from histological review available on DCIS size, histological grade/sub-type, presence and degree of comedo-type necrosis, presence and degree of inflammation and excision status and were included in the present analyses (Table 1). Accurate review of the presence or absence of microinvasion was felt to be too error prone for meaningful analysis; some cases had the original sections submitted for review, but from other cases, new sections had been cut and submitted for re-evaluation. Nevertheless, only 16 of the 1224 cases in this series had definite microinvasion and a further 42 had 'possible' microinvasion in the original histology report. This feature was related to size of DCIS lesion, but not, perhaps surprisingly, to the grade of DCIS (data not shown).

Analysis for treatment arms was repeated, using the sub-set of cases with full pathological data from this review, to confirm that the results were not significantly different from the whole group analysis presented earlier (UK Coordinating Committee on Cancer Research Ductal Carcinoma in situ Working Party, 2003).

One hundred and fifty four of the 1224 cases reviewed $(12.6 \%)$ developed recurrence of disease either DCIS or invasive carcinoma in the ipsilateral breast. Ninety nine $(64 \%)$ developed recurrent DCIS and 55 invasive disease, comparable with the results in analysis of the overall trial.

Univariate analyses and distribution of features of DCIS are shown in Table 1. The DCIS was found to be of high cytonuclear grade (National Pathology Co-ordinating Group, 2005) in $74.6 \%$ of cases $(n=913), 18.4 \%$ were of intermediate grade and only $7.0 \%$ of cases $(n=225)$ were of low cytonuclear grade $(n=86)$. Breakdown by Van Nuys grade (Silverstein et al, 1995) showed that in addition to the 913 patients (as above) with high-grade disease (74.6\%), 212 had DCIS, which was non-high grade but in which necrosis was present $(17.3 \%)$, and 99 patients had non-high-grade DCIS without necrosis $(8.1 \%)$. Comedo-type necrosis, to a greater or lesser extent, was present in all, but 117 cases $(90.4 \%)$ in this series of screen-detected DCIS.

All of the systems of grading of DCIS applied showed a significant association with recurrence of ipsilateral DCIS or invasive disease, as did the predominant growth pattern/architecture of the disease. Patients with a solid morphology as the main architectural pattern of DCIS had a $15.2 \%$ recurrence rate compared with $14.3 \%$ of those with micropapillary DCIS and only $7.3 \%$ of those with predominantly cribriform DCIS. The presence or absence of comedo-type necrosis and the presence of associated chronic inflammation was also associated with increased risk of recurrence of DCIS or progression to invasive cancer in the ipsilateral breast (Table 1).

Intragrade analysis showed that the pure comedo-type cases $(n=483,39.5 \%)$ fared particularly poorly. This grading system recognised a large group of cases in this trial as 'non-pure comedo' type disease (51.0\%).

Re-analysis of cytonuclear grade with the inclusion of an additional particularly aggressive 'pure comedo' group was, therefore, undertaken. Using the definitions applied in this review, this latter group had (i) high-cytonuclear-grade DCIS, (ii) $>50 \%$ solid architecture and (iii) $>50 \%$ of the ducts bore central confluent comedo-type necrosis. This resulted in a new four-tiered system: low (low cytonuclear grade $(7.0 \%$ cases $)$ ), intermediate (intermediate cytonuclear grade $(18.4 \%$ of cases), high (high cytonuclear grade, but not pure comedo (i.e. not predominantly solid architecture or $<50 \%$ ducts bore necrosis) (35.1\%)) and very high (high-grade DCIS of $>50 \%$ solid architecture and $>50 \%$ ducts bearing comedo-type necrosis (39.5\% of cases)). This novel classification system showed a strong relationship with development of ipsilateral recurrence (Table 2a), both overall and separately for DCIS and invasive disease (Figures 1-3). This new classification system, retained significance across the range of sizes of disease (although numbers in the groups are by necessity smaller). Even, for example, for those lesions $10-19 \mathrm{~mm}$ in size, 
Table 2a New grading system - recurrence of ipsilateral DCIS or invasive carcinoma

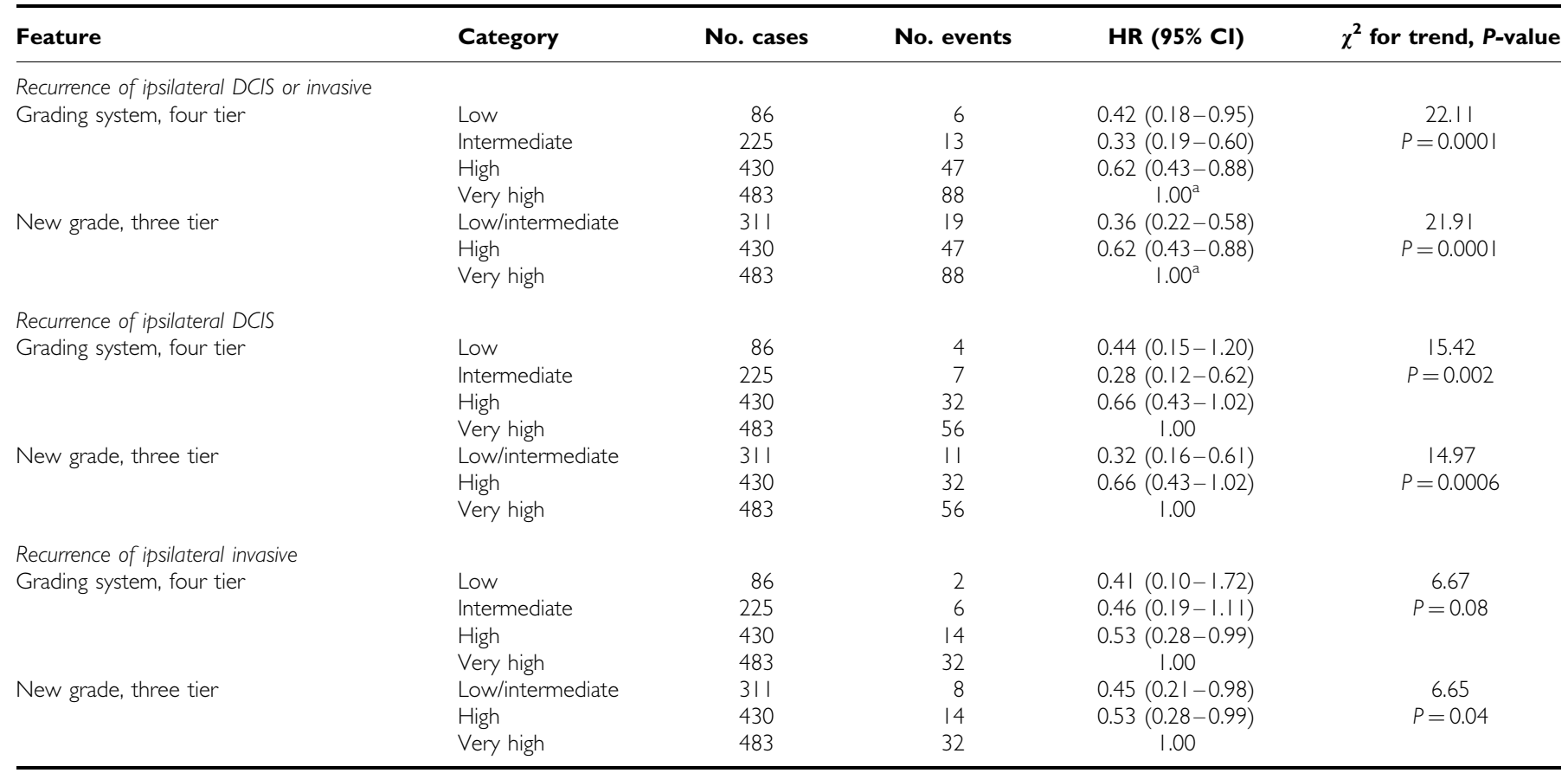

Abbreviations: $\mathrm{Cl}=$ confidence interval; $\mathrm{DCIS}=$ ductal carcinoma in situ; $\mathrm{HR}=$ hazard ratio. ${ }^{a}$ Baseline category. NB: There is one ipsilateral event for which it is unknown whether the recurrence was DCIS or invasive.

Table 2b New grading system for size groups - recurrence of ipsilateral DCIS or invasive carcinoma

\begin{tabular}{|c|c|c|c|c|c|}
\hline Feature & Category & No. cases & No. events & HR (95\% Cl) & $\chi^{2}$ for trend, $P$-value \\
\hline \multicolumn{6}{|l|}{ Tumour size $<9 \mathrm{~mm}$} \\
\hline \multirow[t]{2}{*}{ New grade, three tier } & Low/intermediate & 132 & 3 & $0.21(0.05-0.7 I)$ & 8.57 \\
\hline & High & 108 & 9 & $0.75(0.32-1.71)$ & $P=0.011$ \\
\hline \multicolumn{6}{|l|}{ Tumour size $10-19 \mathrm{~mm}$} \\
\hline \multirow[t]{2}{*}{ New grade, three tier } & Low/intermediate & 116 & 9 & $0.43(0.21-0.90)$ & 8.77 \\
\hline & High & 222 & 23 & $0.55(0.33-0.9 \mid)$ & $P=0.01$ \\
\hline New grade, three tier & Low/intermediate & 62 & 7 & $0.46(0.31-1.15)$ & 4.65 \\
\hline & High & 94 & 14 & $0.46(0.20-1.06)$ & $P=0.09$ \\
\hline & Very high & 112 & 28 & $1.00^{\mathrm{a}}$ & \\
\hline
\end{tabular}

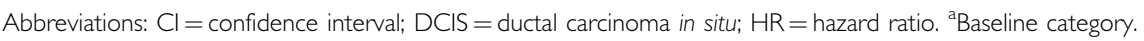

the new system could distinguish a group of patients with very high-grade disease who had a significantly higher risk of developing ipsilateral recurrence of DCIS or invasive carcinoma over the remainder of those with cytonuclear high-grade DCIS (Table 2b).

The maximum dimension of DCIS (the larger size from either original histology report or histological review) ranged from 0.5 to $82 \mathrm{~mm}$ (median $14.5 \mathrm{~mm}$ ). There were 368 patients with DCIS $<10 \mathrm{~mm}$ in size $(30.1 \%), 575(46.9 \%)$ had DCIS measuring $10-19 \mathrm{~mm}$ and 268 patients $(21.9 \%)$ had lesions $\geqslant 20 \mathrm{~mm}$. The total size of DCIS could not be accurately determined in 13 patients. Univariate analysis showed that larger DCIS size $(\geqslant 20 \mathrm{~mm})$ was associated with a higher risk of ipsilateral recurrence.

Despite the inclusion criteria requiring 'complete excision', this was not quantified in the original trial protocol. Defining complete excision as $1 \mathrm{~mm}$ or more distance to the nearest margin for this analysis, it was found that 196 patients (16.0\%) had incompletely excised disease. In 182 patients, the completeness of excision was uncertain $(14.9 \%)$. The majority $(69.1 \%, n=846)$ had DCIS that was completely excised $\geqslant 1 \mathrm{~mm}$; this was associated with a lower risk of ipsilateral recurrence of disease (DCIS or invasive). No association was seen between completeness of excision and DCIS size, or with grade of DCIS (data not shown).

An absolute measurement of the distance to the margins in $\mathrm{mm}$ was available in 637 cases, from the original report or the histological review. The range of distance to the surgical margins was $0-25 \mathrm{~mm}$, the median was $1.5 \mathrm{~mm}$ and the mean $2.8 \mathrm{~mm}$. Some cases of DCIS were assessed as excision 'uncertain' as a categorical variable, as described above, for example when there was disagreement between the original histology report and review. For this reason, there was a greater number of cases with a margin measurement of $<1 \mathrm{~mm}(n=269 ; 42.2 \%)$ than were classified as incompletely excised, as described above $(n=196)$. Of the group with assessable margin width, $214(33.6 \%)$ had disease between 1 and $<5 \mathrm{~mm}$ from the margin and $154(24.2 \%)$ had disease $5 \mathrm{~mm}$ or more from an inked radial margin of excision. Only 29 patients $(4.5 \%)$ had disease $>10 \mathrm{~mm}$ from the margin. Analysis of margin distance (sub-grouped either as $<1 \mathrm{~mm} ; 1$ to $<2 \mathrm{~mm} ; 2$ to 


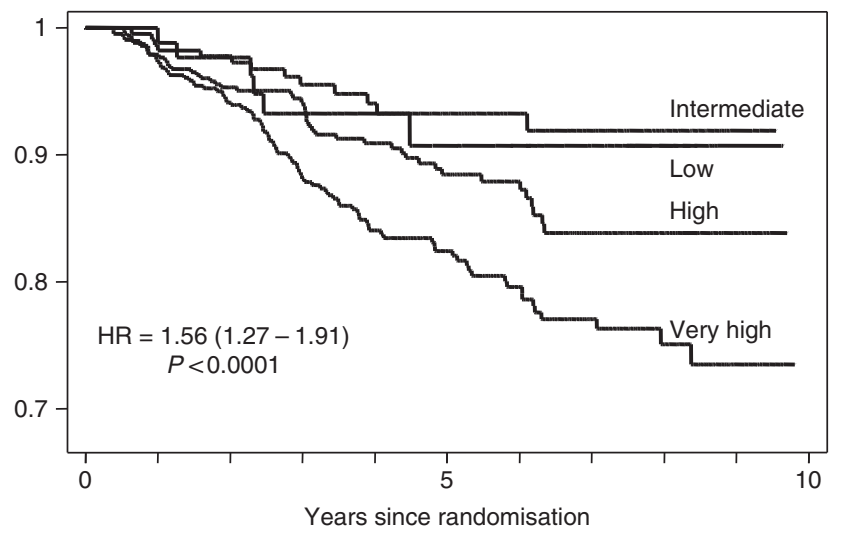

Figure I Recurrence of ipsilateral DCIS or invasive carcinoma by new grading system for DCIS.

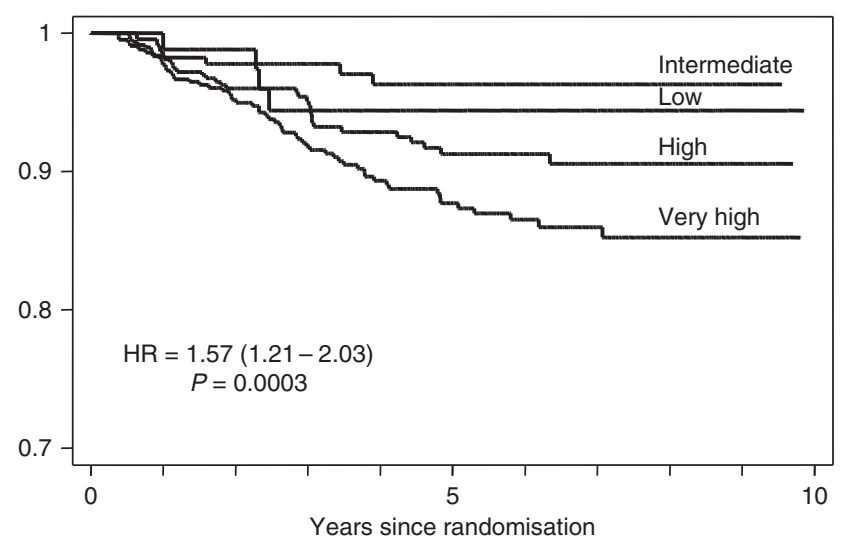

Figure 2 Recurrence of ipsilateral DCIS by new grading system for DCIS.

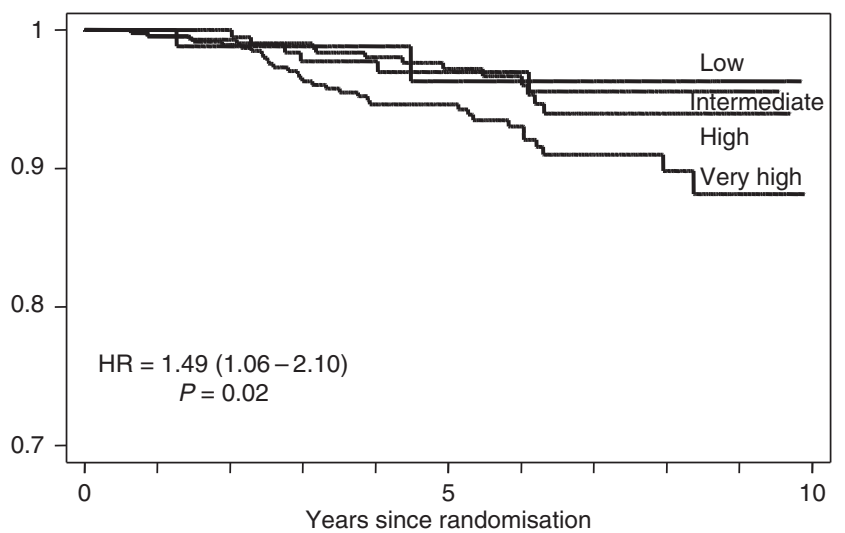

Figure 3 Recurrence of ipsilateral invasive carcinoma by new grading system for DCIS.

$<5 \mathrm{~mm} ; 5 \mathrm{~mm}$ or more) showed that the distance of disease to the margin was a significant predictor of ipsilateral recurrence of disease (DCIS or invasive) (Table 3 ). The DCIS excised by $\geqslant 5 \mathrm{~mm}$ had approximately half the risk of ipsilateral recurrence compared with DCIS excised by $<1 \mathrm{~mm}$.

The presence of chronic inflammation was related to recurrence of ipsilateral disease (Table 1). Of note, this was particularly associated with an increase in progression to ipsilateral invasive disease recurrence rather than recurrent DCIS. Those cases without chronic inflammation had a hazard ratio (HR) for ipsilateral invasive disease recurrence of 0.27 compared with cases in which an inflammatory cell infiltrate was identified. For DCIS recurrence, in the absence of chronic inflammation, the HR was 0.58 . Of note, this feature was very commonly present to some degree ( $76 \%$ of cases) and was related to the grade of DCIS (seen in $21 \%, 55 \%$ and $86 \%$ of cytonuclear grades 1,2 and 3, respectively, $\left.\chi^{2}=250.0, P<0.001\right)$, but was independent of grade of DCIS (and also the new classification system) in multivariate analysis (Table 4).

Multivariate analysis including the new grading four-tier system for DCIS, the receipt of RT, tumour size and completeness of excision is shown in Table 4; the HR of the new very high grade was 2.77 for any ipsilateral recurrence when compared with low- and intermediate-grade DCIS. Multivariate analysis also confirmed that RT reduced the risk of ipsilateral DCIS and invasive recurrence by approximately one-third $(\mathrm{HR}=0.34$, $\mathrm{CI}=0.23-0.52)$ in this large sub-set of pathologically reviewed cases from the main trial. Increasing DCIS size was also of independent significance.

\section{DISCUSSION}

Many of the cases did not have what would now be considered the minimum dataset of features for DCIS reported in the original laboratory (Lester et al, 2009); all the histological features presented here are derived from the central histopathology review. Such review of any large multicentre trial is fraught with difficulties, including the retrieval of histological sections from a large number of different laboratories. This is particularly problematic for trials of DCIS, as more than one surgical procedure is more frequently undertaken than for invasive breast carcinoma. In total, $72.3 \%$ of the cases had material reviewed.

The determination of completeness of excision of DCIS can be difficult for the primary reporting pathologist, but especially in a central review; for this reason, this feature has not been included in the analysis in many papers (de Mascarel et al, 2000; Ottensen et al, 2000). We report details of margin status and distance to margins in the present analysis, but would note that the evaluation of this feature and, in particularly, the measurement of distance to margins cannot be considered precise. Despite this, both completeness of excision as a categorical variable and the distance to margins were found to be of independent significance in predicting for ipsilateral recurrence of disease, highlighting again the significance of this feature in clinical management of DCIS.

No defined margin distance was required for inclusion into this randomised clinical trial. Pragmatically, complete excision was defined as $\geqslant 1 \mathrm{~mm}$ in this pathological review analysis; many will claim this cutoff is too small. The margin width desirable for adequate treatment of pure DCIS remains a topic of major controversy with some of the opinion that the margin should simply be 'tumour free' (Fisher et al, 1993). It has been suggested that a $2 \mathrm{~mm}$ margin is sufficient if RT is also given (Kell and Morrow, 2005), but others recommend that a larger width of tumour-free tissue is appropriate and have shown an increasing HR for local recurrence with decreasing margin clearance in patients with DCIS treated by excision alone (MacDonald et al, 2005). We have found that complete excision $(\geqslant 1 \mathrm{~mm})$ was associated with a lower risk of local recurrence of ipsilateral disease, but the present analysis does not unequivocally assist in distinguishing what margin width is optimal (Table 3 ).

The presence of chronic inflammation was found to be a predictor of a higher risk of ipsilateral recurrence of invasive disease, but not of recurrent DCIS. This was related to, but statistically independent of, cytonuclear grade. The presence of chronic inflammation may be associated with invasive and 
Table 3 Margin distance as a predictor of outcome

\begin{tabular}{|c|c|c|c|c|c|}
\hline End point & Distance to margin ${ }^{a}$ & No. cases & No. events & HR (95\% Cl) & $\chi^{2}$ for trend, $P$-value \\
\hline Ipsilateral DCIS or invasive recurrence & $\begin{array}{l}0-<1 \mathrm{~mm} \\
\geqslant 1 \mathrm{~mm}\end{array}$ & $\begin{array}{l}269 \\
368\end{array}$ & $\begin{array}{l}47 \\
39\end{array}$ & $\begin{array}{c}1.00 \\
0.61(0.41-0.94)\end{array}$ & $\begin{array}{l}4.98 \\
0.03\end{array}$ \\
\hline
\end{tabular}

Abbreviations: $\mathrm{Cl}=$ confidence interval; $\mathrm{DCIS}=$ ductal carcinoma in situ; $\mathrm{HR}=$ hazard ratio. ${ }^{\mathrm{a}}$ Baseline category. ${ }^{\mathrm{b}}$ The smaller of the measurement (i) from the original histology report (if noted) or (ii) from the histological review of slides was used for analysis, unless there was a clear discrepancy when the margin distance was recorded as not assessable.

Table 4 Multivariate analysis for all ipsilateral recurrent events and for recurrence of ipsilateral invasive disease

\begin{tabular}{|c|c|c|c|c|c|c|}
\hline \multirow[b]{2}{*}{ Covariate } & \multicolumn{3}{|c|}{$\begin{array}{l}\text { Recurrence of } \\
\text { all ipsilateral } \\
\text { disease (DCIS } \\
\text { or invasive) }\end{array}$} & \multicolumn{3}{|c|}{$\begin{array}{l}\text { Recurrence of } \\
\text { ipsilateral } \\
\text { invasive } \\
\text { carcinoma }\end{array}$} \\
\hline & $\begin{array}{l}\text { No. } \\
\text { cases }\end{array}$ & HR & $95 \% \mathrm{Cl}$ & $\begin{array}{l}\text { No. } \\
\text { cases }\end{array}$ & HR & $95 \% \mathrm{Cl}$ \\
\hline \multicolumn{7}{|l|}{ New grading system } \\
\hline Low and intermediate & 310 & $1^{\mathrm{a}}$ & & 309 & $1^{a}$ & \\
\hline High & 424 & 1.69 & $0.99-2.89$ & 423 & 0.86 & $0.35-2.11$ \\
\hline Very high & 477 & 2.77 & $1.69-4.57$ & 476 & 1.46 & $0.65-3.31$ \\
\hline \multicolumn{7}{|l|}{$X R T$ received } \\
\hline No XRT & 776 & $1^{\mathrm{a}}$ & & 774 & $1^{a}$ & \\
\hline$X R T$ & 435 & 0.34 & $0.23-0.52$ & 434 & 0.52 & $0.27-0.98$ \\
\hline \multicolumn{7}{|l|}{ Tumour size } \\
\hline $0-0.9 \mathrm{~cm}$ & 368 & $1^{a}$ & & 366 & $\mathrm{l}^{\mathrm{a}}$ & \\
\hline $1.0-1.9 \mathrm{~cm}$ & 575 & 1.67 & $1.07-2.59$ & 574 & 1.89 & $0.89-3.99$ \\
\hline$\geqslant 2 \mathrm{~cm}$ & 268 & 2.67 & $1.66-4.30$ & 268 & 1.89 & $0.80-4.49$ \\
\hline \multicolumn{7}{|l|}{ Excision } \\
\hline Complete & 838 & $1^{\mathrm{a}}$ & & 835 & $1^{\mathrm{a}}$ & \\
\hline Incomplete & 192 & 1.47 & $0.98-2.22$ & 192 & 1.01 & $0.46-2.21$ \\
\hline Uncertain & 181 & 1.82 & $1.21-2.73$ & 181 & 2.35 & $1.27-4.37$ \\
\hline \multicolumn{7}{|l|}{ Inflammation } \\
\hline Absent & & & & 294 & $\mathrm{I}^{\mathrm{a}}$ & \\
\hline Present & & & & 914 & 3.11 & $1.06-9.13$ \\
\hline
\end{tabular}

Abbreviations: $\mathrm{Cl}=$ confidence interval; $\mathrm{DCIS}=$ ductal carcinoma in situ; $\mathrm{HR}=$ hazard ratio; $\mathrm{XRT}=$ radiotherapy. ${ }^{\mathrm{a}}$ Baseline category.

angiogenic factors, a local milieu, which facilitates invasion through the basement membrane. An association with the development of invasive carcinoma thus seems plausible, but the association with recurrence independent of features such as completeness of excision is difficult to explain and clearly requires further investigation. Further evaluation of the nature of the chronic inflammation was not possible using the routinely stained sections in this review, but seems warranted.

Patient age was significantly associated with disease recurrence in univariate analyses $(P=0.05)$, but this was not retained in the multivariate model. However, the majority of patients recruited to the trial had DCIS detected through the UK National Health Service Breast Screening Programme available to all women aged $50-64$ years (at that time). Thus, only 92 of the 1224 women in this analysis were $\leqslant 50$ years of age, so comment cannot be made regarding young patient age and risk of recurrence from this clinical trial.

The distribution of cytonuclear grade of the DCIS in this UK trial is different to that in other series such as the EORTC 10853 trial; in the latter study, only $40 \%$ of cases were poorly differentiated, $28 \%$ were moderately differentiated and $32 \%$ were well differentiated (Bijker et al, 2001). In comparison, the proportion of DCIS of high grade in the present series is large (74.6\%). Although this is likely, at least in part, to be a reflection of the era in which the patients were recruited to the trial, high-grade DCIS remains the commonest form identified in the United Kingdom. In the Sloane Project/UK audit of screen-detected DCIS, $62 \%$ of 1101 DCIS, in which grade was recorded, were of high grade (Thomas et al, 2008). Although difficulties regarding the reproducibility of grade of DCIS between pathologists have been described (Ellis et al, 2006), in the present review, all cases were examined by one pathologist, reducing this element of variation.

DCIS is a heterogeneous disease morphologically, immunohistochemically and genetically (Patchefsky et al, 1989; Bobrow et al, 1994; Meijnen et al, 2008; Vincent-Salomon et al, 2008) and sub-typing can identify lesions with differing risks of progression and recurrence. In this study, risk of ipsilateral recurrence was related to sub-type of disease, using many of the grading systems described (Holland et al, 1994; Poller et al, 1994; Silverstein et al, 1995; National Pathology Co-ordinating Group, 2005), as shown in Table 1, or indeed the older historical method of sub-typing based on architecture and cell size. The presence of comedo-type necrosis also predicted outcome, as shown in other studies (Fisher et al, 1995, 1999b; Silverstein et al, 1996). Growth pattern/architecture also reflected risk of recurrence, as shown in the EORTC DCIS trial (Bijker et al, 2001). In the present large series reviewed by a single breast pathologist, many of the earlier described prognostic features of DCIS showed a relationship with risk of ipsilateral recurrence of disease; the question then remains as to which of these features is/are most valuable?

In this study, we have identified a group of patients with a particularly poor outcome, which has not been shown earlier. The novel finding in this series is that those women who had DCIS not only of high nuclear grade, but also of pure $(>50 \%)$ solid architecture with extensive necrosis (in $>50 \%$ of ducts) had a significantly worse outcome than those with a high cytonuclear grade alone. Thus, the division of DCIS into low-, intermediate- and high-grade forms, as applied in present systems of classification (National Pathology Co-ordinating Group, 2005; Lester et al, 2009), may not be optimal. The relatively small proportion of disease of low or intermediate grade, and the few events in these groups, makes it difficult to draw definitive conclusions from the present series, but patients with low- or intermediate-grade DCIS fared similarly well. Of note, low- and intermediate-grade DCIS have also been shown to have similar immunohistochemical profiles, distinct from that of high-grade disease (Meijnen et al, 2008).

The system we describe suggests that DCIS is better classified by an alternative three group system: (i) a group of low- and intermediate-cytonuclear-grade disease, (ii) high-nuclear-grade DCIS of non-solid architecture or with $<50 \%$ ducts bearing necrosis and (iii) high-nuclear-grade DCIS with extensive confluent comedo-type necrosis ( $>50 \%$ ducts) and with solid architecture. These groups have ipsilateral recurrence rates of 
DCIS or invasive disease of $6.1 \%, 10.9 \%$ and $18.2 \%$, respectively. Although this proposed system of classification clearly requires further validation in other series, it may potentially aid in the recognition of more clinically relevant groups of patients with
DCIS, namely women with low-risk disease who may not require further adjuvant therapy to the breast and a group with a particular high risk of recurrence who may benefit from maximal local therapy.

\section{REFERENCES}

Anderson TJ, Lamb J, Donnan P, Alexander FE, Huggins A, Muir BB, Kirkpatrick AE, Chetty U, Hepburn W, Smith A, Prescott RJ, Forrest P (1991) Comparative pathology of breast cancer in a randomised trial of screening. Br J Cancer 64: 108-113

Baxter NN, Virnig BA, Durham SB, Tuttle TM (2004) Trends in the treatment of ductal carcinoma in situ of the breast. J Natl Cancer Inst 17: $443-448$

Bijker N, Peterse JL, Duchateau L, Julien JP, Fentiman IS, Duval C, Di Palma S, Simony-Lafontaine J, de Mascarel I, van de Vijver MJ (2001) Risk factors for recurrence and metastasis after breast-conserving therapy for ductal carcinoma-in-situ: analysis of European Organisation for Research and Treatment of Cancer Trial 10853. J Clin Oncol 19: $2263-2271$

Bijker N, Meijnen P, Peterse JL, Bogaerts J, Van Hoorebeeck I, Julien JP, Gennaro M, Rouanet P, Avril A, Fentiman IS, Bartelink H, Rutgers EJ, EORTC Breast Cancer Cooperative Group; EORTC Radiotherapy Group (2006) Breast-conserving treatment with or without radiotherapy in ductal carcinoma-in-situ: ten-year results of European Organisation for Research and Treatment of Cancer randomized phase III trial 10853a study by the EORTC Breast Cancer Cooperative Group and EORTC Radiotherapy Group. J Clin Oncol 24: $3381-3387$

Bobrow LG, Happerfield LC, Gregory WM, Spingall RD, Millis RR (1994) The classification of ductal carcinoma in situ and its association with biological markers. Semin Diagn Pathol 11: 199-207

de Mascarel I, Bonichon F, MacGrogan G, de Lara CT, Avril A, Picot V, Durand M, Mauriac L, Trojani M, Coindre JM (2000) Application of the Van Nuys prognostic index in a retrospective series of 367 ductal carcinomas in situ of the breast examined by serial macroscopic sectioning: practical considerations. Breast Cancer Res Treat 61: 151 - 159

Dodwell D, Clements K, Lawrence G, Kearins O, Thomson CS, Dewar J, Bishop H (2007) Sloane Project Steering Group. Radiotherapy following breast-conserving surgery for screen-detected ductal carcinoma in situ: indications and utilisation in the UK. Interim findings from the Sloane Project. Br J Cancer 97: 725-729

Ellis IO, Coleman D, Wells C, Kodikara S, Paish EM, Moss S, Al-Sam S, Anderson N, Bobrow L, Buley I, Connolly CE, Dallimore NS, Hales S, Hanby A, Humphreys S, Knox F, Lowe J, Macartney J, Nash R, Parham D, Patnick J, Pinder SE, Quinn CM, Robertson AJ, Shrimankar J, Walker RA, Winder R (2006) Impact of a national external quality assessment scheme for breast pathology in the UK. J Clin Pathol 59: 138-145

Fisher B, Costantino J, Redmond C, Fisher E, Margolese R, Dimitrov N, Wolmark N, Wickerham DL, Deutsch M, Ore L, Mamounas E, Poller W, Kavanah M (1993) Lumpectomy compared with lumpectomy and radiation-therapy for the treatment of intraductal breast-cancer. New Eng J Med 328: 1581 - 1586

Fisher B, Dignam J, Wolmark N, Mamounas E, Costantino J, Poller W, Fisher ER, Wickerham DL, Deutsch M, Margolese R, Dimitrov N, Kavanah M (1998) Lumpectomy and radiation therapy for the treatment of intraductal breast cancer: findings from National Surgical Adjuvant Breast and Bowel Project B-17. J Clin Oncol 16: 441-452

Fisher B, Dignam J, Wolmark N, Wickerham DL, Fisher ER, Mamounas E, Smith R, Begovic M, Dimitrov NV, Margolese RG, Kardinal CG, Kavanah MT, Fehrenbacher L, Oishi RH (1999a) Tamoxifen in the treatment of intraductal breast cancer: national Surgical Adjuvant Breast and Bowel Project B-24 randomised control trial. Lancet 353: $1993-2000$

Fisher ER, Costantino J, Fisher B, Palekar AS, Redmond C, Mamounas E (1995) Pathologic findings from the National Surgical Adjuvant Breast Project (NSABP) Protocol B-17. Intraductal carcinoma (ductal carcinoma in situ). The National Surgical Adjuvant Breast and Bowel Project Collaborating Investigators. Cancer 75: 1310-1319

Fisher ER, Dignam J, Tan-Chiu E, Costantino J, Fisher B, Paik S, Wolmark N (1999b) Pathologic findings from the National Surgical Adjuvant Breast

Project (NSABP) 8 year up-date of protocol B-17: intraductal carcinoma. Cancer 86: $429-438$

Holland R, Peterse JL, Millis RR, Eusebi V, Faverly D, van de Vijver MJ, Zafrani B (1994) Ductal carcinoma in situ: a proposal for a new classification. Semin Diagn Pathol 11: 167-180

Julien JP, Bijker N, Fentiman IS, Peterse JL, Delledonne V, Rouanet P, Avril A, Sylvester R, Mignolet F, Bartelink H, Van Dongen JA (2000) Radiotherapy in breast conserving treatment for ductal carcinoma in situ: first results of the EORTC randomised phase 3 trial 10853. Lancet 355: $528-533$

Kell MR, Morrow M (2005) An adequate margin of excision of ductal carcinoma in situ. Br Med J 331: 789-790

Lester SC, Bose S, Chen YY, Connolly JL, de Baca ME, Fitzgibbons PL, Hayes DF, Kleer C, O'Malley FP, Page DL, Smith BL, Weaver DL, Winer E (2009) Members of the Cancer Committee, College of American Pathologists. Protocol for the examination of specimens from patients with ductal carcinoma in situ of the breast. Arch Pathol Lab Med 133: $15-25$

MacDonald HR, Silverstein MJ, Mabry H, Moorthy B, Ye W, Epstein MS, Holmes D, Silberman H, Lagios M (2005) Local control in ductal carcinoma in situ treated by excision alone: incremental benefit of larger margins. Am J Surg 190: $521-525$

Meijnen P, Peterse JL, Antonini N, Rutgers EJ, van de Vijver MJ (2008) Immunohistochemical categorisation of ductal carcinoma in situ of the breast. Br J Cancer 98: 137-142

National Pathology Co-ordinating Group (2005) Pathology Reporting of Breast Disease. NHS BSP Publication: Sheffield

NHS Breast Screening Programme. Annual Review (2008) http://www. cancerscreening.nhs.uk/breastscreen/publications/2008review.html

Ottensen GL, Graversen HP, Blichert-Toft M, Christensen IJ, Andersen JA (2000) Carcinoma in situ of the female breast. 10 year follow-up results of a prospective nationwide study. Breast Cancer Res Treat 62: 197-210

Patchefsky AS, Schwartz GF, Finkelstein SD, Prestipino A, Sohn SE, Singer JS, Feig SA (1989) Heterogeneity of intraductal carcinoma of the breast. Cancer 63: $731-741$

Poller DN, Silverstein MJ, Galea M, Locker AP, Elston CW, Blamey RW, Ellis IO (1994) Ideas in pathology. Ductal carcinoma in situ of the breast: a proposal for a new simplified histological classification association between cellular proliferation and c-erbB-2 protein expression. Mod Pathol 7: 257-262

Sakorafas GH, Farley DR (2003) Optimal management of ductal carcinoma in situ of the breast. Surg Oncol 12: 221-240

Silverstein MJ, Poller DN, Waisman JR, Colburn WJ, Barth A, Gierson ED, Lewinsky B, Gamagami P, Slamon DJ (1995) Prognostic classification of breast ductal carcinoma-in-situ. Lancet 345: 1154-1157

Silverstein MJ, Lagios MD, Craig PH, Waisman JR, Lewinsky BS, Colburn WJ, Poller DN (1996) A prognostic index for ductal carcinoma in situ of the breast. Cancer 77: 2267-2274

Thomas J, Hanby A, Pinder S, Ellis I, Macartney J, Clements K, Lawrence G, Bishop H (2008) Sloane Project Steering Group. Implications of inconsistent measurement of ER status in non-invasive breast cancer: a study of 1,684 cases from the Sloane Project. Breast J 14: 33-38

UK Coordinating Committee on Cancer Research Ductal Carcinoma in situ Working Party (2003) Radiotherapy and tamoxifen in women with completely excised ductal carcinoma in situ of the breast in the UK, Australia, and New Zealand: randomised controlled trial. Lancet 362: 95- 102

Vincent-Salomon A, Lucchesi C, Gruel N, Raynal V, Pierron G, Goudefroye R, Reyal F, Radvanyi F, Salmon R, Thiery JP, Sastre-Garau X, SigalZafrani B, Fourquet A, Delattre O (2008) Breast cancer study group of the Institut Curie. Integrated genomic and transcriptomic analysis of ductal carcinoma in situ of the breast. Clin Cancer Res 14: 1956-1965 